\title{
International Outsourcing and Long-Run Growth in a Variety Expansion Model
}

\author{
Ken-ichi Hashimoto \\ Graduate School of Economics, Kobe University, Kobe, Japan \\ Email: hashimoto@econ.kobe-u.ac.jp
}

Received May 31, 2012; revised June 26, 2012; accepted July 23, 2012

\begin{abstract}
We develop a North-South trade model including the opportunity for outsourcing in a variety expansion framework and derive the effect of an increase in outsourcing on long-run growth. We find that the effect of increased outsourcing on the growth rate of product variety is contingent on the labor size of the Northern and Southern economy. In particular, if the relative labor size of South to North is smaller, outsourcing the production of intermediate goods to Southern economy can have negative effects on economic growth.
\end{abstract}

Keywords: Outsourcing; Long-Run Growth; North-South Trade; Variety Expansion Model

\section{Introduction}

Many developed countries have opened up to trade and are increasingly outsourcing production. Firms shift the production of some components abroad and assemble the components into final goods at home. According to empirical work by Feenstra and Hanson [1] and Crinò [2], the share of international outsourcing by US firms was $11.61 \%$ in 1990 and $18.1 \%$ in 2002 . According to surveys, as reported by Ito et al. [3], 21\% of manufacturing industries in Japan use offshoring. Since outsourcing influences the structure of labor markets, the effects are an important contemporary economic issue in offshoring economy.

In their pioneering work, while Glass and Saggi [4] develop a North-South trade model including the opportunity for outsourcing, they only employ a quality ladder approach ${ }^{1}$. They demonstrate that increased outsourcing always encourages long-run growth. In this paper, endogenous technical progress drives productivity growth in the form of variety expansion. A study closest to ours is Naghavi and Ottaviano [7], who consider the endogenous determinants of offshoring in a variety expansion model. They compare the growth rate of offshoring economy with that of no offshoring economy. Turning to our model, we focus on the property of offshoring economy only and examine the effect of increased international outsourcing on long-run growth in offshoring economy. Thus, this paper adopts the exogenous opportunity of international outsourcing, where firms cannot offshore more than a certain share in the same way as Glass and Saggi [4] and Rodrigues-Clare [8], and reexamines their results using a variety expansion framework of Grossman and Helpman [9] in which Northern country engages in innovative R \& D and Southern country engages in imitative $\mathrm{R} \& \mathrm{D}^{2}$.

Our contribution to the literature is to present a NorthSouth trade model incorporating international outsourcing opportunities and show how it can be used to shed light on the relationship between international outsourcing and long-run growth. We show that the effect of increased outsourcing on long-run growth depends upon the structure of North and South; i.e., population size, the productivity of research and development ( $\&$ D), etc. Our main finding is that the increased outsourcing of production in the North proves to encourage (discourage) long-run growth when the population size of the South is larger (smaller).

\section{The Model}

\subsection{Households}

Assume two countries, North $(N)$ and South $(S)$, with $L_{N}$ and $L_{S}$ being the respective number of consumers in each country. The utility function is:

$$
\begin{aligned}
& U_{i}=\int_{0}^{\infty} \mathrm{e}^{-\rho t} \ln X_{i}(t) \mathrm{d} t, X_{i}(t)=\left(\int_{0}^{n} x_{i}(j)^{\alpha} \mathrm{d} j\right)^{1 / \alpha}, \\
& 0<\alpha<1
\end{aligned}
$$

where $\rho$ is the rate of time preference, $x_{i}(j)$ is the de-

\footnotetext{
${ }^{1}$ For a static analysis of the effect of increased outsourcing, see Feenstra and Hanson [5] and Arndt [6].

${ }^{2}$ For a different approach to long-run growth, Rodrigues-Clare [8] analyses the increased ofshoring in a process innovation framework of Eaton and Kortum [10].
} 
mand of household $i(\in N, S)$ for variety $j$ of the mass varieties $n=n_{N}+n_{S}$. Given instantaneous utility, the demand function of $x_{i}(j)$ is given by $x_{i}(j)=\sigma_{j} E_{i} / p(j)$ where $\sigma_{j} \equiv p(j)^{-\alpha /(1-\alpha)} / \int_{0}^{n} p(j)^{-\alpha /(1-\alpha)} \mathrm{d} j$,

$E_{i}$ is consumption expenditure in country $i$, and $p(j)$ is the price of $x(j)$. The aggregate demand function of $x(j)$ is then:

$$
x(j)=\sigma_{j} \frac{E}{p(j)}
$$

where

$$
x(j)=x_{N}(j) L_{N}+x_{S}(j) L_{S} \text { and } E=E_{N} L_{N}+E_{S} L_{S} .
$$

Using these equations, it is easy to establish that utility-maximizing total expenditure obeys the familiar Euler equation $\dot{E}_{i} / E_{i}=r-\rho$, where $r$ is the rate of interest determined in the global financial market. The Euler equation for country $i$ can then be easily arranged into:

$$
\dot{E} / E=r-\rho
$$

\subsection{Firm Sectors}

Local monopolists holding patents for the goods produce differentiated products. To obtain patents, a firm must first succeed in R \& D. Economies where product innovation takes place are in the North and their imitation takes place in the South. First, consider the production of North. The production in the R \& D sector takes the following form:

$$
\dot{n}=a_{N} R_{N} n
$$

where $a_{N}$ is the productivity of innovative $\mathrm{R} \& \mathrm{D}, R_{N}$ is the number of $\mathrm{R} \& \mathrm{D}$ workers and the presence of $n$ captures knowledge spillover in innovative R \& D. We assume the random imitation of Northern products. More specifically, a given Northern product is assumed to be copied with an instantaneous probability of $h=\dot{n}_{S} / n_{N}$ during a time interval $\mathrm{d} t$, given that the range of Southern goods increases by $\dot{n}_{S}$ during $\mathrm{d} t$. Let $V_{N}$ denote the expected present value of profits earned by Northern monopoly firms that succeed in innovative R \& D.

$$
r V_{N}=\pi_{N}+\dot{V}_{N}-h V
$$

Now define $\varphi=n_{N} / n$ as the share of Northern goods in all variety goods. Using this definition, we can rewrite the Poisson rate of imitation $h$ as

$$
h=\frac{\dot{n}_{S}}{n_{S}} \frac{1-\varphi}{\varphi} .
$$

We assume free entry in the R \& D sector. Therefore, given the $\mathrm{R} \& \mathrm{D}$ technology, the following condition holds:

$$
V_{N} a_{N} n=w_{N}
$$

where $w_{N}$ is the wage rate in the North.

Final output $x(j)$ is produced with two intermediate goods $Z_{N}$ and $Z_{S}$. The intermediate $\operatorname{good} Z_{i}$ is produced in country $i=N, S$. One worker is required to produce one unit of intermediate goods $\left(z_{N}, z_{S}\right)$. More specifically, if a firm produces $x(j)$ units of final output goods, its marginal cost (MC) becomes:

$$
\operatorname{MC}(j)=(1-\gamma) w_{N}+\gamma w_{S}
$$

where $w_{S}$ denotes the wage rate in the South, and $\gamma$ is the share of intermediate goods from the South and the remaining $1-\gamma$ is the share of intermediate goods from the North. Then the total cost $(T C)$ of $x(j)$ is given by:

$$
T C(j)=\left[(1-\gamma) w_{N}+\gamma w_{S}\right] x(j) .
$$

Hence, unit cost is the same for all differentiated products in the North. Given the price elasticity of demand $1 /(1-\alpha)$, the representative Northern producer sets the price:

$$
p_{j}=p_{N}=\frac{1}{\alpha}\left[(1-\gamma) w_{N}+\gamma w_{S}\right], j \in\left(0, n_{N}\right)
$$

and earns profit:

$$
\pi_{N}=(1-\alpha) \sigma_{N} E
$$

Turn now to the South. The production function of the imitative R \& D sector takes the following form:

$$
\dot{n}_{S}=a_{S} R_{S} n_{S}
$$

where $a_{S}$ is the productivity of imitative $\mathrm{R} \& \mathrm{D}, R_{S}$ is the number of $\mathrm{R} \& \mathrm{D}$ workers and the presence of $n_{S}$ captures knowledge spillover in imitative $\mathrm{R} \& \mathrm{D}$. Let $V_{S}$ denote the expected present value of profits earned by Southern monopoly firms that succeed in imitative $\mathrm{R} \& \mathrm{D}$, as defined by:

$$
r V_{S}=\pi_{S}+\dot{V}_{S}
$$

We assume free entry in the R \& D sector. Therefore, given the $\mathrm{R} \& \mathrm{D}$ technology, the following condition holds.

$$
V_{S} a_{S} n_{S}=w_{S}
$$

Final output firms that succeed in imitative R \& D can produce goods with labor inputs with a marginal cost of $w_{S}$. The Southern firms charge the monopoly price. We assume wide gap equilibrium where the Southern monopoly price does not exceed the marginal cost of production in the North. We then have:

$$
p_{j}=p_{S}=\frac{1}{\alpha} w_{S}, j \in\left(0, n_{S}\right)
$$

and the profits of Southern firms are:

$$
\pi_{S}=(1-\alpha) \sigma_{S} E
$$




\subsection{Labor Market Conditions}

In the North, there are two sources of labor demand: innovative R \& D and intermediate goods. In the R \& D sector, $R_{N}=\dot{n} / n a_{N}$ workers are employed. In the manufacturing of intermediate goods, labor demand is $n_{N} z_{N}$. Using Shepard's lemma, we obtain $z_{N}=\partial T C_{N} / \partial w_{N}$.

$$
L_{N}=\frac{1}{a_{N}} \frac{\dot{n}}{n}+(1-\gamma) n_{N} x_{N}
$$

Conversely, in the South there are three sources of labor demand: imitative R \& D, the manufacture of Southern production goods, and intermediate goods exported to the North. In the imitative R \& D sector, $R_{S}=\dot{n}_{N} / n_{N} a_{S}$ workers are employed. Labor demand is $n_{S} x_{S}$ for Southern manufacturing production and $n_{N} z_{S}$ for the intermediate production exported to the North. Using Shepard's lemma, we obtain $z_{S}=\partial T C_{N} / \partial w_{S}$.

$$
L_{S}=\frac{1}{a_{S}} \frac{\dot{n}_{S}}{n_{S}}+n_{S} x_{S}+\gamma n_{N} x_{N}
$$

\subsection{Steady State Equilibrium and the Effect of Increased Outsourcing}

We now consider the market equilibrium conditions. In the steady state, $\dot{n} / n=\dot{n}_{S} / n_{S}=g$ is satisfied. We then have following equations (see the Appendix for their derivation):

$$
\begin{gathered}
L_{N}=\frac{g}{a_{N}}+(1-\gamma) \frac{1}{1-\gamma+\gamma \omega} \frac{\alpha}{1-\alpha} \frac{\rho \phi+g}{a_{N}} \\
L_{S}=\frac{g}{a_{S}}+\frac{\alpha}{1-\alpha} \frac{\rho+g}{a_{S}}+\gamma \frac{1}{1-\gamma+\gamma \omega} \frac{\alpha}{1-\alpha} \frac{\rho \phi+g}{a_{N}}
\end{gathered}
$$

where $\omega\left(\equiv w_{S} / w_{N}\right)$. From (15) and (16), we can explicitly solve for the growth rate as follows.

$$
\begin{aligned}
g= & \frac{a_{S}}{1 /(1-\alpha)-\left(a_{S} / a_{N}\right)(\gamma /(1-\gamma))} \\
& \times\left[L_{S}-\frac{1}{a_{S}} \frac{\alpha}{1-\alpha} \rho-\frac{\gamma}{1-\gamma} L_{N}\right]
\end{aligned}
$$

It can be easily confirmed that the long-run growth rate depends on the population size of the North-South countries, the parameter for the share of production outsourced, and the remaining parameters. We assume the following parameter conditions for positive rates of growth $(g>0)$.

$$
L_{S}>\frac{1}{a_{S}} \frac{\alpha}{1-\alpha} \rho+\frac{\gamma}{1-\gamma} L_{N}, \frac{1}{1-\alpha} \frac{a_{N}}{a_{S}}>\frac{\gamma}{1-\gamma}
$$

Now consider the effect of increased outsourcing on long-run economic growth. An increase in internationally outsourcing is interpreted as an increase in the ratio of foreign production of outsourced intermediate goods to domestically produced intermediate goods. This shift in production from home to foreign arises with changes in the economic environment, e.g. changes in local contents requirement or quotas on the usage of foreign inputs, and is described by an increase in $\gamma^{3}$. The purpose of this paper is not to discuss the desirable level of outsourcing share but to show the relationship between the proportion of outsourcing and the rate of economic growth. From (17), the impact on long-run growth is:

$$
\frac{d g}{d \gamma}=\Phi\left[L_{S}-\frac{1}{a_{S}} \frac{\alpha}{1-\alpha} \rho-\frac{a_{N}}{a_{S}} \frac{1}{1-\alpha} L_{N}\right]
$$

where

$$
\Phi \equiv \frac{1}{\left(1 /(1-\alpha)-\left(a_{S} / a_{N}\right)(\gamma /(1-\gamma))\right)^{2}} \frac{a_{S}^{2}}{a_{N}} \frac{1}{(1-\gamma)^{2}}>0
$$

Then we have obtain the following results:

$$
\begin{aligned}
& \frac{\mathrm{d} g}{\mathrm{~d} \gamma}>0 \text { for } L_{S}>\frac{1}{a_{S}} \frac{\alpha}{1-\alpha} \rho+\left(\frac{a_{N}}{a_{S}} \frac{1}{1-\alpha}\right) L_{N} \\
& \frac{\mathrm{d} g}{\mathrm{~d} \gamma} \leq 0 \text { for } L_{S} \leq \frac{1}{a_{S}} \frac{\alpha}{1-\alpha} \rho+\left(\frac{a_{N}}{a_{S}} \frac{1}{1-\alpha}\right) L_{N}
\end{aligned}
$$

This is formally stated in the following proposition.

Proposition 1: Increased outsourcing in Northern country to Southern country $(\gamma)$ raises (resp. lowers) the growth rate of product variety if the labor in Southern country is larger (resp. smaller): $L_{S}>$ (resp. $\left.<\right) \alpha \rho / a_{S}(1-\alpha)+$ $\left[a_{N} / a_{S}(1-\alpha)\right] L_{N}$.

Intuitively, the effect is as follows. An increase in outsourcing suggests more of the labor force in the North is devoted to the innovative R \& D sector, and this increases economic growth. In contrast, outsourcing has a negative effect on economic growth through a decrease in the labor employed in imitative R \& D sector in the South. Thus, increased outsourcing can have a negative effect on long-run growth depending on the labor endowment in the Northern-Southern country. If the relative labor size of South to North is smaller, the negative effect overweighs. Figure 1 depicts the graphical result.

\section{Conclusion}

This paper constructs a North-South trade model with outsourcing opportunity in a variety expansion framework and examines the effect of increased outsourcing on the economic growth. In the literature of quality ladder based growth model, Glass and Saggi [4] find that the

\footnotetext{
${ }^{3}$ Weakening local contents requirements or relaxing import quotas on intermediate goods are considered for a policy to have positive effect on outsourcing opportunities. This approach for modeling outsourcing opportunities is followed by Glass and Saggi [4].
} 


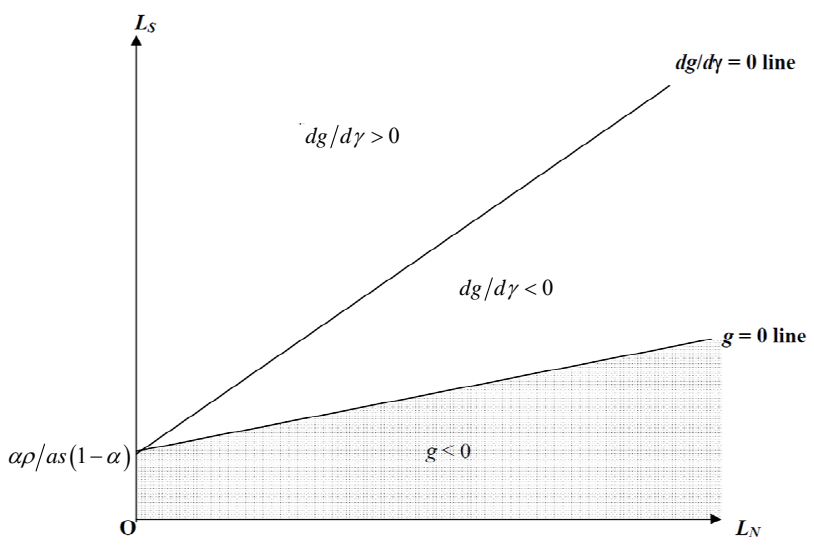

Figure 1. The effect of outsourcing.

effects of outsourcing have positive on growth rate. In a variety expansion growth model, however, we show that the effect of an increase in outsourcing on long-run growth is contingent on the labor size of the North-South economy. The mixed results of an increase in outsourcing do not appear in the quality-ladder based growth model.

\section{Acknowledgements}

The author would like to thank an anonymous referee for helpful comments and suggestions. This research is financially supported by the Grants-in-Aid for Young Scientists (B), JSPS. All remaining errors are, of course, my own.

\section{REFERENCES}

[1] R. C. Feenstra and G. H. Hanson, "Globalization, Outsourcing, and Wage Inequality," American Economic Review, Vol. 86, No. 2, 1996, pp. 240-245.

\section{Appendix}

Using $\dot{V}_{N} / V_{N}+\dot{n} / n=\dot{w}_{N} / w_{N}$ from (2), (4), (5) and (7) we have

$$
\dot{E} / E-\dot{w}_{N} / w_{N}+\dot{n} / n+h+\rho=(1-\alpha) \sigma_{N} E a_{N} n / w_{N} .
$$

In the steady state, $E / w_{i}$ is satisfied to be constant and $\dot{n} / n=\dot{n}_{S} / n_{S}=g$. Then, using (1), (6), $\phi=n_{N} / n$, $h=g(1-\phi) / \phi$, and $\omega \equiv w_{S} / w_{N}$, we obtain:

$$
g / \varphi+\rho=\frac{1-\alpha}{\alpha} a_{N}[1-\gamma+\gamma \omega] \frac{1}{\varphi} n_{N} x_{N} .
$$

[2] R. Crinò, "Offshoring, Multinationals and Labour Market: A Review of the Empirical Literature," Journal of Economic Surveys, Vol. 23, No. 2, 2009, pp. 197-249. doi:10.1111/j.1467-6419.2008.00561.x

[3] B. Ito, E. Tomiura and R. Wakasugi, "Dissecting Offshore Outsourcing and R \& D: A Survey of Japanese Manufacturing Firms," Discussion Paper 07-E-060, Research Institute of Economy, Trade, and Industry, 2007.

[4] A. J. Glass and K. Saggi, "Innovation and Wage Effects of International Outsourcing," European Economic Review, Vol. 45, No. 1, 2001, pp. 67-86. doi:10.1016/S0014-2921(99)00011-2

[5] R. C. Feenstra and G. H. Hanson, "Foreign Investment, Outsourcing and Relative Wages," In: R. C. Feenstra, G. M. Grossman and D. A. Irwin, Eds., The Political Economy of Trade Policy: Papers in Honor of Jagdish Bhagwait, MIT Press, Cambridge, 1996, pp. 89-127.

[6] S. W. Arndt, "Globalization and the Open Economy," North American Journal of Economics and Finance, Vol. 8, No. 1, 1997, pp. 71-79. doi:10.1016/S1062-9408(97)90020-6

[7] A. Naghavi and G. Ottaviano, "Offshoring and Product Innovation," Economic Theory, Vol. 38, No. 3, 2009, pp. 517-532. doi:10.1007/s00199-007-0322-8

[8] A. Rodriguez-Clare, "Offshoring in a Ricardian World," American Economic Journal: Macroeconomics, Vol. 2, No. 2, 2010, pp. 227-258. doi:10.1257/mac.2.2.227

[9] G. Grossman and E. Helpman "Endogenous Product Cycles," The Economic Journal, Vol. 101, No. 408, 1991, pp. 1214-1229. doi:10.2307/2234437

[10] J. Eaton and S. Kortum, "Technology, Trade, and Growth: A Unified Framework," European Economic Review, Vol. 45, No. 4-6, 2001, pp. 742-755. doi:10.1016/S0014-2921(01)00129-5

Substituting (A1) into (13) gives (15).

Similarly, using $\dot{V}_{S} / V_{S}+\dot{n}_{S} / n_{S}=\dot{w}_{S} / w_{S}$ from (2), (9), and (10) and the steady state conditions, we have

$$
g+\rho=(1-\alpha) \sigma_{S} E a_{S} n_{S} / w_{S} .
$$

Then from Equations (1) and (11), we obtain:

$$
g+\rho=\frac{1-\alpha}{\alpha} a_{S} n_{S} x_{S} .
$$

Substituting (A1) and (A2) into (14) gives (16). 